\title{
Humanitarismo e a Favela Global: Violência Urbana e Ação Humanitária no Río de Janeiro*
}

\author{
Carolina Moulin** e Jana Tabak***
}

\section{Introdução}

$(1$ futuro da ação humanitária, especialmente diante da contínua violência e crescente urbanização de espaços em todo o mundo, ocupa um lugar central nos debates não só entre pesquisadores, mas também entre governantes e organizações não governamentais. Se

\footnotetext{
* Artigo recebido em 15 de dezembro de 2013 e aprovado para publicação em 10 de junho de 2014. Este artigo é resultado do projeto de pesquisa Ação humanitária em situações de não guerra (HASOW), financiado pelo IDRC/Canadá. Gostaríamos de agradecer a equipe do projeto, Paulo Esteves e Rob Muggah, bem como o IDRC pelo apoio. Um agradecimento especial também a Isadora de Andrade e Mariana Marques de Medeiros, assistentes de pesquisa, e às pessoas do MSF Brasile da Cruz Vermelha Brasileira que compartilharam conosco suas experiências. Sobre o projeto, ver: $<$ www.hasow.org $>$.

** Ph.D. em Relações Internacionais pela McMaster University, Canadá, e professora assistente do Instituto de Relações Internacionais da Pontifícia Universidade Católica do Rio de Janeiro (IRI/PUC-Rio). E-mail: cmoulin.iri@gmail.com.

*** Doutora em Relações Internacionais pelo Instituto de Relações Internacionais da Pontifícia Universidade Católica do Rio de Janeiro (IRI/PUC-Rio) e professora agregada na mesma instituição. E-mail: jtabak@gmail.com.
} 
até então cidades eram espaços ignorados por atores humanitários, processos de urbanização de grande escala somados à proliferação de inseguranças e falta de capacidade de proteção por parte de governantes e atores locais mudam tal perspectiva, e cidades, em particular aquelas localizadas no chamado "Sul Global", 1 tornam-se, então, o novo alvo dessas organizações.

Tal relação entre ação humanitária e contextos de violência urbana depende da articulação discursiva entre dois processos que tradicionalmente caminhavam de forma independente. $O$ primeiro processo é o chamado "vácuo de proteção" ou "crise de proteção", isto é, a crescente percepção entre membros da comunidade humanitária acerca da falha de iniciativas e projetos humanitários que buscam reduzir e/ou prevenir sofrimento humano. Esta "crise de identidade" (BARNETT; SNYDER, 2008) no campo humanitário se tornou particularmente evidente na década de $1990^{2}$ e, independentemente dos esforços contínuos para definir, padronizar e institucionalizar as atividades humanitárias, ${ }^{3}$ este campo ainda é altamente politizado, permeado por muitas disputas não resolvidas e perspectivas antagônicas. Isso se reflete na proliferação de termos que falam mais sobre as incertezas e ansiedades do complexo e dinâmico campo humanitário do que sobre a resolução de dilemas diários enfrentados por seus profissionais. Alívio, assistência, proteção legal, proteção social, autoproteção, proteção comunitária e resiliência: estes são apenas alguns exemplos do vocabulário diverso e prolífico que hoje compõe o já complicado mundo dos humanitários.

O segundo processo refere-se à recente apropriação, no campo humanitário, de discussões sobre urbanização e seu impacto sobre a violência, exclusão social e, especialmente, sobre as deficiências do Estado em prover proteção legal e social para importantes segmentos das populações urbanas. Isto é, a compreensão dos processos de urbanização em países em desenvolvimento enquanto "favelização", caracterizada por movimentos populacionais não controlados, per- 
mitiu a reificação de certas cidades do Sul Global como cidades frágeis (KROONING; KRUIJT, 2007) marcadas por zonas de violência e número crescente de pessoas desprotegidas. Favelas são, nesse contexto, um produto de processos e forças globais, bem como espaços com os quais os Estados nacionais emergentes ainda estão pouco preparados para lidar. Nesse sentido, a expansão do mandato humanitário para áreas urbanas apresenta-se como opção razoável e possível diante tanto da incerteza acerca dos limites e potenciais da ação humanitária quanto do sofrimento humano e insegurança que permeiam a vida dos moradores de favelas.

Somada a esta articulação entre a "crise de identidade" do campo humanitário e os impactos da urbanização na vida das populações mais pobres, a experiência das organizações humanitárias em situações de conflito armado e de desastre natural nas cidades, como Porto Príncipe e Karachi, legitima a intervenção de tais atores em espaços de violência urbana supostamente similares, como Dhaka, Nairóbi, Joanesburgo e Rio de Janeiro.

É justamente diante desse cenário que as favelas do Rio de Janeiro se tornam parte da política global de assistência e proteção humanitária de atores importantes, como o Comitê Internacional da Cruz Vermelha (CICV) e o Médicos Sem Fronteiras (MSF), que passam a liderar projetos e iniciativas visando a redução do impacto da violência no dia a dia dos moradores de favelas. Apesar do caso do Rio de Janeiro não ser o único, a análise dele permite explorar alguns dos desafios e problemas quando atores humanitários começam a atuar no Sul (urbano). Por meio de uma análise do projeto do MSF de assistência médica nas favelas do Rio de Janeiro, em particular o trabalho desenvolvido durante dois anos no Complexo do Alemão, este artigo busca compreender a relação entre atores humanitários e contextos urbanos com foco na avaliação dos próprios trabalhadores humanitários acerca de suas experiências. 
Com base em entrevistas conduzidas com participantes do projeto, argumenta-se aqui que a maioria dos dilemas enfrentados por esses projetos humanitários reside na tendência à universalização e, consequentemente reificação da lógica social de espaços urbanos na periferia e, portanto, na implementação de programas de proteção relativamente homogêneos. Neste contexto, os moradores das favelas são percebidos e produzidos essencialmente como vítimas vulneráveis. Como será analisado ao longo do artigo, esta não é uma prerrogativa exclusiva dos atores humanitários no caso do Rio de Janeiro. Entendimentos sobre a favela por atores globais, por exemplo, trabalhadores humanitários, são resultado de construções históricas da favela realizadas por meio de lentes essencialistas e antagônicas, que produzem concepções estereotipadas desses espaços urbanos. Muitas dessas representações são, então, simplificadas no discurso humanitário, autorizando a inclusão da favela no espaço humanitário global.

Um segundo desafio a ser discutido neste artigo diz respeito à difícil relação das agências humanitárias com os parceiros locais e estruturas governamentais, que resulta de uma percepção equivocada acerca das estruturas de governança e dinâmicas sociais das favelas. Em contextos urbanos caracterizados como "outras situações de violência”, comoé o caso das favelas, a cooperação com estruturas locais de organização e provisão social, sejam elas governamentais ou não, é um mal necessário. Dificuldades em estabelecer o diálogo com os provedores de serviços locais e a incapacidade de compreender políticas locais de proteção social podem se revelar prejudiciais para a garantia da assistência humanitária nesses contextos. Por exemplo, avaliações equivocadas acerca das hierarquias de poder locais e clivagens sociais, particularmente nas favelas, também desafiam a capacidade do MSF de ser fiel ao próprio princípio de imparcialidade.

O terceiro e último dilema em relação à confluência entre humanitarismo e violência urbana diz respeito à dimensão temporal das iniciativas de proteção humanitária que tendem, no caso do Rio de Janeiro, 
a responder aos surtos de violência e/ou situações específicas que mobilizam a atenção da população em geral. Estas situações de violência são particulares e provocam diferentes - muitas vezes até incoerentes - respostas institucionais. A curta duração de alguns projetos humanitários aliada às dificuldades em se adequar aos tempos heterogêneos dos contextos urbanos podem comprometer tanto os potenciais resultados desses projetos quanto a confiança de comunidades locais em relação aos atores não estatais enquanto capazes de ajudar.

O artigo está dividido em três partes. A primeira seção analisa a relação entre urbanização, a emergência da favela como um problema social e de segurança no Rio de Janeiro e sua recente inclusão no "radar" da ação humanitária global. Em seguida, o artigo narra o início das atividades do MSF no Rio de Janeiro e analisa mais especificamente o projeto no Complexo do Alemão entre 2007 e 2009. Por fim, a última seção discute os dilemas enfrentados pelo MSF ao associar violência urbana e proteção humanitária: universalidade, cooperação e temporalidade. Esta seção conclui com algumas lições aprendidas relativas à proteção e assistência humanitária em situações de não guerra, enfatizando a mudança de estratégias do MSF no Brasil e em outros lugares.

\section{Favelas, Violência Urbana e Humanitarismo: Uma Relação Complexa}

A ONU-Habitat estima que, em 2030, 60\% da população mundial viverá em cidades, sendo estas localizadas majoritariamente nos países em desenvolvimento. Em especial para os jovens, os centros urbanos são associados à prosperidade econômica, à geração de emprego e a oportunidades educacionais. ${ }^{4}$ Além disso, as cidades evocam imaginários de agilidade, mobilidade social e diversidade cultural. Tais características ajudam a explicar o porquê das pessoas morarem na cidade. No entanto, como Duijsens $(2010)^{5}$ ressalta, as cidades são ao 
mesmo tempo espaços de progresso e destituição. Processos de urbanização provocaram a expansão tanto em número quanto em tamanho dos espaços de pobreza e contenção social, frequentemente percebidos e tratados como zonas de violência e marginalização.

Estima-se que um quarto da população urbana mundial reside em favelas, totalizando aproximadamente um bilhão de pessoas. Percebida como "favelização" "6 espaço urbano, a urbanização em cidades no Sul Global provoca tensão entre os políticos e alimenta o medo entre os moradores das cidades. Entre as ameaças associadas ao crescimentos das cidades, encontram-se problemas ambientais relacionados à questão sanitária, poluição, informalidade crescente e um mercado de trabalho precário, além de problemas relacionados à (i)mobilidade urbana, entre outros.

Em pleno diálogo com tais receios, uma breve análise da literatura sobre processos de urbanização esbarra em recorrentes generalizações e afirmações universalizantes sobre a natureza desses movimentos, sua relação com a violência, pobreza e atividades ilegais, tais como tráfico de drogas e contrabando, e o amplo reconhecimento do "vácuo governamental" combinado às "vulnerabilidades crescentes". Os exemplos abaixo iluminam algumas das percepções sobre a urbanização global e as ameaças que esse processo supostamente impõe à segurança humana - desde a falta de proteção legal até desafios coletivos de caráter biológico, como pandemias. Estes também reforçam a crença de que o mundo de favelas está se tornando um novo espaço para ação humanitária:

A rápida e anárquica urbanização do nosso planeta, a ampliação do hiato entre áreas ricas e favelas, violência disseminada e ausência de leis em áreas que não oferecem serviços públi$\cos$, a chegada de refugiados, pessoas deslocadas, e de imigrantes para as cidades, e a cidade como polo atrativo para grupos armados. Tudo isso chama atenção de organizações huma- 
nitárias e agências de desenvolvimento [...]. Estados não podem esperar controlar a violência nas cidades somente através de medidas de segurança (HARROFF-TAVEL, 2010, p. 349-350, ênfases nossas).

$\mathrm{O}$ entrelaçamento entre pobreza, marginalização e violência em áreas pobres e negligenciadas das cidades aumenta a segregação urbana e contribui para a emergência das "zonas interditas", caracterizada por uma "ausência do Estado de Direito". Na ausência de autoridades legais e da representação da Lei e da Ordem, essas áreas de fato constituem um "vácuo de governança" (DUIJSENS, 2010, p. 360 , ênfases nossas).

Apesar de muitos esperarem que a urbanização equivalha à melhor qualidade de vida, este movimento não inclui todos, e muitas pessoas pobres são rapidamente absorvidas pelas favelas urbanas. Urbanização, de fato, é um perigo para a saúde de algumas populações vulneráveis, e esta mudança demográfica ameaça criar um desastre humanitário (PATEL; BURKE, 2012, p. 741, ênfases nossas).

As consequências da violência para saúde, marginalização, e/ou negligência das populações vulneráveis são significativas. Dado que os ambientes urbanos são o futuro espaço de muitas intervenções humanitárias, é importante continuar a fomentar uma atitude de reflexão, inovação e flexibilidade (LUCCHI, 2012, p. 101, ênfases nossas).

Um "planeta de favelas" constituído a partir de processos de urbanização (DAVIS, 2006) é percebido não apenas como uma das principais faces do mundo em desenvolvimento, mas também como espaços marginais particulares. ${ }^{7}$ Vale ressaltar que estes espaços são mar- 
ginais em pelo menos dois sentidos: como fora da lei (e portanto ilegais - desde a ocupação ilegal da terra a uma economia local baseada no contrabando de produtos e drogas) e como fora da ordem (confusos e incontroláveis - isto é, desafiam a ordem territorial da cidade com suas ruas e esquinas planejadas, a ordem burocrática imposta pelas autoridades estatais com seus impostos e sistema judicial e/ou a ordem social convencional com seus serviços públicos, regras de civilidade e transparência). Por exemplo, a análise alarmista de Patel e Burke (2012) acerca dos processos de urbanização entendidos como desastres humanitários (citada acima) é interessante na medida em que apropria referências metafóricas a forças naturais de forma a apresentar um tipo de movimento incontrolável. Inclusive, tal metáfora dialoga com outra "megatendência" (FERRIS, 2011) humanitária: desastres e calamidades naturais.

O argumento geral articula, nesse sentido, uma visão simplista da urbanização como um processo desgovernado e sem controle associado à produção de zonas territoriais de destituição/criminalidade e fora do controle estatal. Consequentemente, esses territórios e seus habitantes são excluídos do aparato estatal de proteção e, portanto, enquadrados em formas de governança social alternativas e, frequentemente, violentas. Processos de urbanização indisciplinados e globalizados produzem cidades frágeis, caracterizadas por estruturas sociais profundamente desiguais e altas taxas de letalidade. Essas estruturas sociais (reproduzidas territorialmente em espaços de contenção da cidade) produzem pessoas - em necessidade e em risco - que não podem recorrer a meios tradicionais de acesso a recursos públicos e proteção estatal. É justamente essa combinação particular da profunda falta de recursos e infraestrutura sociopolítica permeada pela violência que provoca a demanda por formas alternativas de proteção. ${ }^{8}$ Neste contexto, atores humanitários emergem como opção capaz de minimizar o impacto deletério da urbanização, e as favelas urbanas transformam-se em um novo espaço para expansão do para- 
digma alívio-proteção. Apesar de existir uma ampla literatura sobre estudos urbanos críticos, ${ }^{9}$ a maioria dos autores e profissionais que refletem sobre a interseção entre humanitarismo e urbanização tendem a enfatizar os aspectos negativos da última. Urbanização, concebida desta forma, tende a produzir cidades falidas, cujo aspecto mais visível e negativo são as favelas e seus moradores.

No caso das favelas do Rio de Janeiro, essa leitura foi historicamente construída por governantes, jornalistas e acadêmicos (VALLADARES, 2005). O termo favela, desde suas primeiras referências no fim do século XVIII e início do século XIX, foi associado ao influxo de populações rurais para as cidades. O Morro da Providência, ou Morro da Favela, foi uma das primeiras favelas no cenário urbano do Rio. Depois da Guerra de Canudos (1895-1896), ex-soldados assentaram-se em barracos em um morro no centro do Rio. De acordo com a narrativa mais recorrente, o nome favela foi uma referência a um arbusto comum na zona rural baiana. Apesar de registros históricos apontarem que o Morro da Favela não foi a primeira favela - assentamentos anteriores, densamente povoados e com condições de moradia bastante precárias, foram registrados no Caju, Mangueira e Serra Morena (todos datam de 1881) -, "foi o Morro da Favela que fez história” (VALLADARES, 2005, p. 26).

Baseado em uma cuidadosa análise de documentos históricos e pesquisa acadêmica acerca das favelas no século XX, Valladares (2005, p. 33-35) identifica algumas características centrais que marcaram as primeiras representações desses espaços e que sustentam o "mito fundacional" das favelas: (i) o crescimento precário e rápido; (ii) o difícil acesso devido à topografia montanhosa; (iii) a propriedade coletiva da terra (associando seus moradores a comunidades tribais); (iv) o caráter rebelde, em que Estado e instituições públicas estavam ausentes; (v) a liderança de uma figura carismática que "desviou as pessoas de seus deveres, defendendo publicamente a insurreição contra as leis" (VALLADARES, 2005, p. 34); (vi) o comportamento 
moral degradante dos moradores (roubo, promiscuidade, preguiça); e, finalmente, (vii) o universo exótico e perigoso, cujos efeitos poderiam impactar outros territórios e populações. Somente depois dos anos 1920, o termo favela passa a ser considerado um "nome adequado, uma nova categoria para definir um habitat empobrecido, ilegalmente ocupado e irregular, onde não há o respeito às normas e frequentemente localizado nos morros" (VALLADARES, 2005, p. 26).

Mesmo antes da percepção da favela como forma dominante de ocupação do território no espaço urbano, esta já é tida como um problema social. As características socialmente construídas (e essencializadas) da favela operam como traço naturalizado de todas as favelas, informando, assim, políticas públicas, intervenções não governamentais de atores locais e globais e até mesmo o próprio entendimento entre líderes comunitários e a mídia local.

Um quadro de referência moralizante e mercadológico de ação marcou a administração pública dos territórios e dos moradores das favelas, com forte ênfase nos discursos de revitalização e higienização. ${ }^{10}$ Neste contexto, há tentativas de limpar e civilizar as favelas por meio de políticas sanitárias, de vacinação e de resgate moral, ${ }^{11}$ além da proibição de construção de novos prédios, remoções forçadas e modernização da infraestrutura da favela, consideradas necessárias para curar essa patologia social e estética. A combinação de abordagens populistas fundamentadas no discurso da "salvação" e da apropriação capitalista desses territórios, por meio de programas de moradia, estratégias de turismo e projetos locais de empreendedorismo, persiste até hoje como estratégia através da qual atores governamentais e não governamentais têm pensado e interagido sobre/com as favelas do Rio e suas populações.

Entretanto, pesquisas apontam que essas políticas falharam em termos da contenção do avanço das favelas. O censo demográfico de 2010 mostrou que o Rio de Janeiro tem a maior população de favelas 
no Brasil, com mais de 1,3 milhão de pessoas morando em 763 favelas, o que equivale a $22 \%$ de toda a população brasileira (GALDO, 2011). Como afirma Perlman (2007, p. 3), "apesar de três décadas de esforços políticos no Brasil - primeiro para erradicar as favelas e depois para melhorá-las e integrá-las à cidade -, tanto o número de favelas quanto o número de pessoas morando nas favelas continuam a crescer".

Como analisaremos na próxima seção, as experiências dos Médicos Sem Fronteiras nas favelas do Rio de Janeiro foram gradualmente construídas a partir de muitas dessas concepções sobre a favela. Neste contexto, o movimento dos atores humanitários em direção ao Sul urbano contribuiu fortemente para o surgimento de uma "favela global", que internacionaliza aquelas mesmas características das favelas que durante tanto tempo discriminaram e estigmatizaram seus moradores.

\section{Experiências do MSF no Rio de Janeiro: das ruas aos complexos}

Criado em 1971 na França, o Médicos Sem Fronteiras tornou-se uma das principais organizações internacionais não governamentais humanitárias (OING) em todo o mundo. Com uma história marcada por uma abordagem combativa e arrojada em situações de conflito, por um interesse central na assistência médica e pela manutenção do princípio da neutralidade (TERRY, 2002), o MSF tem sido pioneiro no seu campo de atuação e foi a primeira ONGI humanitária a atuar no Rio de Janeiro. Entretanto, vale notar que as favelas do Rio já apresentam uma longa história de relações com pessoas e organizações internacionais: desde os anos 1950, ONGs internacionais, pesquisadores internacionais e turistas têm ido às favelas tanto para dar assistência aos moradores pobres quanto para aprender sobre (e consumir) suas realidades. A Rocinha, localizada na Zona Sul do Rio de Janeiro com mais de 30 mil habitantes, é o melhor exemplo de uma 
favela verdadeiramente global, com a presença de albergues, turistas, filmes e projetos internacionais permanentes (FREIRE-MEDEIROS, 2009). Nos anos 1960, os Peace Corps enviaram muitos voluntários para ajudar os favelados no Rio, o que poderia ser considerado o primeiro registro de uma organização estrangeira ${ }^{12}$ a organizar a sua presença nas favelas da cidade (VALLADARES, 2005).

A experiência do MSF em espaços urbanos envolve quatro "cenários": (i) os contextos de guerra urbana (cidades em países que vivem guerras civis ou internacionais, como Bagdá); (ii) emergências (cidades que enfrentam catástrofes naturais e epidemias, como o surto de cólera em Porto Príncipe); (iii) situações de violência (cidades com "rotina implacável de violência diária", como Tegucigalpa e Rio); e, finalmente, (iv) contexto onde há "populações negligenciadas e marginalizadas morando em favelas" (LUCCHI, 2012, p. 27). É interessante notar como as favelas constituem uma categoria específica de atuação da organização, independentemente da presença de violência. De certa forma, pressupõe-se que moradores de favelas marginalizadas têm necessidades médicas independentemente do contexto particular da "favela". Os dois últimos cenários estão relacionados no caso das intervenções do MSF no Rio (apesar de este ser considerado exemplo apenas do terceiro cenário, i.e., situações de violência armada, mas não de guerra).

A confluência prática desses cenários é exemplificada pelo recente programa da organização chamado "Sobreviventes Urbanos" (USV). Em parceria com a agência de fotografia NOOR e Darjeeling Produções, o USV é um projeto de multimídia que busca narrar histórias de vida das favelas, localizadas em seis cidades na África, América Latina e Sul Asiático. ${ }^{13}$ A situação dos moradores das favelas é considerada, segundo o relatório do MSF sobre o projeto, uma crise médica humanitária por três razões principais: condições de vida extremas - o espaço das favelas condiciona certas formas de necessidade em razão da violência, de condições precárias de moradia, 
densidade populacional etc. -; marginalização - moradores das favelas enfrentam taxas de crimes mais altas e são frequentemente discriminados -; e o fato de serem negligenciados tanto pela sociedade civil quanto pelas autoridades públicas.

Essas três justificativas para a presença do MSF em favelas urbanas reiteram e reproduzem características associadas às representações históricas das comunidades nessas favelas. $\mathrm{O}$ fato de o MSF destacar seis cidades, todas situadas em países em desenvolvimento do Sul Global, ${ }^{14}$ intensifica a associação entre cidades falidas, violência urbana e pobreza como um fenômeno do terceiro mundo. Diante das imagens disponibilizadas pelo projeto, um espectador menos atento poderia apresentar certa dificuldade em diferenciar os lugares e as situações representadas. As imagens, apesar de refletirem locais específicos, constituem uma representação geral que associa essas realidades diversas a uma concepção da favela global e homogênea. ${ }^{15}$

Apesar do foco em atividades destinadas ao alívio do sofrimento humano, muitos projetos conduzidos pelo MSF no Rio de Janeiro, desde 1993, envolveram atividades de proteção. Por exemplo, de 1997 a 2001, o MSF Brasil conduziu um projeto de treinamento para moradores de favelas desenvolverem sua capacidade de liderança. As primeiras incursões do MSF no Rio de Janeiro, no início dos anos 1990, através do projeto direcionado a crianças em situação de rua, não podem ser classificadas segundo o modelo tradicional de assistência humanitária defendido por muitos profissionais da organização. Como argumentado na seção anterior, contextos urbanos demandaram uma adaptação das vocações e práticas das organizações humanitárias, aproximando o MSF do debate acerca do "vácuo de proteção".

\section{A Unidade de Emergência do Complexo do Alemão}

Os primeiros projetos do MSF no Brasil começaram no início da década de 1990 no estado do Amazonas e em Roraima, com foco no 
combate à epidemia de cólera e ao forte crescimento da incidência de malária, respectivamente. Enquanto o MSF atuava no Norte do país, a cidade do Rio de Janeiro testemunhou dois eventos de extrema violência em 1993: as chacinas da Candelária e de Vigário Geral. Ambos os acontecimentos tiveram ampla repercussão nacional e internacional, mobilizando grupos da sociedade civil, ONGs e a mídia. A mensagem era muito clara: o Rio de Janeiro era uma cidade partida, ${ }^{16}$ na qual grande parte da população vivia em condição de exclusão social e perigo constante.

Diante desse cenário, o MSF começou a trabalhar no Rio de Janeiro, sendo as crianças de rua o principal foco das atividades. Em parceria com outras instituições, o MSF desenvolveu o projeto que buscava retirar as crianças da rua por meio de um serviço de saúde multidisciplinar. Mais tarde, em 1995, o MSF estabeleceu uma clínica em Vigário Geral, voltada para todos os moradores da comunidade. Além disso, o MSF deu cursos de liderança, cujos alunos mais tarde criaram a ONG Movimento Organizado de Gestão Comunitária (Mogec), que, em 1998, começou a administrar a clínica. Nesta mesma época, o MSF também ofereceu atendimento médico semanal debaixo do viaduto da Leopoldina, no centro da cidade, onde 450 pessoas viviam em condições extremas. Um ano depois, o projeto foi finalizado quando esse grupo de pessoas foi transferido para o Complexo da Maré como parte de um amplo projeto do governo estatal.

Em 2007, houve uma nova "ruptura de equilíbrio", ou, nos próprios termos do MSF, "breaking the balance", quando algo muito específico acontece e o MSF precisa reagir. No dia 27 de junho, uma enorme operação policial ocorreu no Complexo do Alemão, deixando dezenove pessoas mortas. Como um trabalhador humanitário do MSF Brasil $^{17}$ comentou, "este evento aponta para uma nova dinâmica da violência, que é muito mais intensa e apresenta um número maior de vítimas". Em outras palavras, era o cenário perfeito para uma ação do MSF, isto é, quando necessidades médias e humanitárias coincidem. 
Considerado um dos maiores complexos de favelas da cidade, o Complexo do Alemão está situado na Zona Norte do Rio de Janeiro. Compreende uma área equivalente a 296 mil campos de futebol, composta por um grupo de quinze favelas e mais de 60 mil habitantes. Na década de 1920, parte do território onde o Complexo está situado pertencia a Leonard Kaczmarkiewicz, um fazendeiro polonês que foi apelidado pelos moradores locais como "Alemão" - nome dado também ao morro, onde uma das favelas foi estabelecida. No fim dos anos 1940, grandes avenidas foram construídas na região, atraindo, primeiro, imigrantes vindos do Nordeste brasileiro e, mais tarde, com a industrialização daquela área, os trabalhadores assalariados.

Com uma história já marcada por conflitos entre gangues e intervenções policiais violentas, o Complexo do Alemão testemunhou uma enorme operação policial - com o apoio das Forças Armadas nacionais - no dia 27 de junho de 2007 com o objetivo de combater o tráfico de drogas. A operação durou cerca de oito horas: 1.350 policiais entraram nas favelas, carregando 1.080 armas e 180 mil balas (GLOBAL JUSTICE, 2007). Ao final da operação, dezenove pessoas foram mortas e cerca de sessenta moradores das favelas foram feridos. Não havia atendimento médico de emergência, nem as ambulâncias eram capazes de circular no Complexo em razão da irregularidade do terreno e dos riscos para a segurança dos próprios profissionais da saúde. A resposta pública à operação policial variava desde a demanda por ações ainda mais repressivas até forte crítica em relação ao número de mortos.

O crescente nível de violência no Alemão e a atenção da mídia destinada a este território em particular atraíram o MSF para a região do Complexo. Segundo um dos entrevistados, "este tipo de operação policial foi o que o MSF chama de "ruptura do equilíbrio"”. Em outras palavras, a troca de tiros tornou o Alemão, em termos simbólico e material, uma crise humanitária médica. 
As necessidades humanitárias foram claramente apresentadas: condições de vida extremas combinadas à presença governamental através do uso da força resultaram em um contexto no qual moradores de favelas se tornaram extremamente vulneráveis à violência, particularmente em contextos de intervenção policial. Ao mesmo tempo, o MSF pressupôs que os moradores não teriam acesso ao atendimento médico básico nem na favela nem nas proximidades do Complexo. Muitas das iniciativas do projeto do Alemão eram baseadas em conhecimento adquirido previamente na Cité du Soleil e em Martissant, favelas em Porto Príncipe, no Haiti, onde o MSF trabalhou durante muitos anos. O projeto piloto no Alemão presumiu que a violência empreendida por gangues, as condições de vida dos moradores e as necessidades médicas locais eram similares àquelas identificadas em Porto Príncipe.

O projeto do MSF no Complexo do Alemão tinha como objetivo o salvamento de pessoas feridas por bala em situações de emergência. O projeto foi organizado em três etapas: resgate, estabilização de pacientes e, finalmente, encaminhamento para hospitais públicos localizados fora do Complexo. Com o apoio da associação de moradores local, o MSF recrutou pessoas que moravam em diferentes favelas do Complexo. Estes profissionais deveriam facilitar o acesso do MSF às vítimas, chamando a organização toda vez que encontrassem alguém ferido por bala que precisasse de ajuda. O resgate era feito por uma van - que o MSF transformou em uma ambulância -, pequena o suficiente para circular pelas ruelas das favelas e desviar dos bloqueios. Ao encontrar a vítima, o MSF provia assistência emergencial e encaminhava o paciente para o hospital mais próximo (na maioria dos casos, o Hospital Getúlio Vargas, pertencente à rede estadual de saúde). Logo surgiu a primeira limitação do projeto: durante as operações policiais ou tiroteios, não era possível circular no Complexo por motivos de segurança e, portanto, tornou-se inviável atender e transportar os feridos. Como afirmou um entrevistado: "Em muitas ocasiões, 
nós não podíamos sair da clínica. Apenas deitávamos no chão para nos proteger e esperávamos até o final do tiroteio." Em outras palavras, quando a presença do MSF era mais necessária a fim de minimizar a vulnerabilidade e o risco da população local, a organização não conseguia agir.

O complexo de favelas foi percebido como um ambiente de alto risco para os trabalhadores humanitários em função não apenas da violência armada e dos recorrentes confrontos entre traficantes de drogas e policiais, mas também devido ao sentimento de indiferença dos criminosos e moradores das favelas em relação à presença do MSF. Segundo um dos entrevistados:

Diferente da experiência em trabalhar no [país $\mathrm{x}],{ }^{18}$ onde o MSF era o único ator a prover tratamento de saúde para cerca de trezentas pessoas, no Complexo do Alemão não importava se estávamos lá ou não. Enquanto no [país x] éramos muito poderosos, no Rio eu tive encontros com traficantes de drogas nos quais eles diziam que tudo bem se eu ficasse, mas tanto fazia se eu fosse embora. Me senti extremamente inseguro por causa desse sentimento de indiferença em relação ao nosso trabalho.

Outro desafio em relação ao resgate e à estabilização dos pacientes foi a organização espacial da favela, que dificultou a circulação dentro do Complexo. A clínica do MSF estava localizada na Fazendinha, que compreende seis favelas, onde resider aproximadamente $25 \%$ dos moradores do Complexo. ${ }^{19}$ Dependendo da localização das vítimas, o resgate pela van levava muito tempo para chegar. Além disso, em alguns casos, os pacientes estavam mais próximos do hospital do que da clínica do MSF. O problema de acesso às vítimas somou-se às dificuldades em estabelecer parcerias de trabalho com instituições de saúde pública. A terceira fase do projeto envolvia o encaminhamento dos pacientes para os hospitais locais nas proximidades do Alemão. 
Mudanças frequentes na administração do hospital inviabilizaram o estabelecimento de uma parceria institucional de longo prazo com o MSF. Além disso, em razão da estrutura precária do Hospital Getúlio Vargas, o principal centro de saúde pública nesta área aceitava somente casos que eram previstos por lei. Pacientes acompanhados ou sob os cuidados de um terceiro, por exemplo, não eram aceitos pelo hospital. Diante disso, em alguns casos, o MSF precisou deixar o paciente na porta do hospital e ir embora a fim de garantir que a pessoa entrasse sozinha na instituição e fosse, então, hospitalizada.

Os problemas enfrentados pela organização, segundo uma avaliação interna, derivam de uma transposição inadequada dos modelos de assistência médica e alívio do sofrimento humano adotados em Cité du Soleil e Martissant. Ao pressupor que as duas realidades eram similares, o MSF buscou adaptar a bem-sucedida experiência nas favelas haitianas para prover ajuda às vítimas civis no Complexo do Alemão. Entretanto, diferente do caso do Rio, o MSF no Haiti participava de todo o sistema médico local, coordenando desde os serviços de emergência até os hospitais. Um dos entrevistados argumentou que, "quando o MSF pensou na possibilidade de replicar o projeto no Rio, pensava-se que os dois cenários eram muito parecidos. No entanto, está claro hoje que os contextos são muito diferentes, apesar de certas similaridades". Enfim, pode-se afirmar que as dificuldades do MSF para implementar o projeto no Alemão refletem as consequências não intencionais de importação de um modelo sem atentar para o contexto no qual este será de fato desenvolvido.

Além disso, ao delinear o projeto, o MSF pressupôs que as necessidades médicas dos moradores do Complexo do Alemão eram negligenciadas, seja porque não tinham acesso a serviços médicos já oferecidos na região ou porque não havia centros médicos na área do Complexo. No entanto, percebeu-se logo que esta era uma assunção equivocada: os residentes saíam da favela para ter acesso a serviços públicos básicos disponíveis na vizinhança, sendo a única exceção os cri- 
minosos, que temiam ser presos pela polícia ao se aproximarem de instituições governamentais. "Há uma estação policial próxima ao Hospital Getúlio Vargas e, muitas vezes, quando nós chegávamos lá trazendo um jovem ferido, o policial fazia uma série de perguntas antes que pudéssemos entrar", contou um entrevistado.

Isso nos leva a outra questão - neste caso, ética - com a qual o MSF precisou lidar no projeto no Complexo do Alemão. De acordo com o princípio da universalidade, todos os moradores tinham acesso à clínica do MSF, sendo o único pré-requisito para ser atendido deixar a arma do lado de fora. Em pouco tempo, traficantes de drogas começaram a procurar a clínica em busca de assistência do MSF e, ao longo dos dois anos de projeto, a maioria dos pacientes eram criminosos. Eventualmente, a clínica do MSF ficou conhecida informalmente entre os moradores como a "clínica dos traficantes".

Apesar de todos esses desafios e iniciativas frustradas, vale ressaltar que o apoio psicológico oferecido aos moradores foi uma das atividades mais bem-sucedidas. A equipe do MSF notou que um número significativo de queixas de pacientes relativas à falta de sono, dores no corpo, forte dor de cabeça e estresse psicológico eram consequências de experiências traumáticas. Em dois anos, segundo a avaliação de um dos participantes, ninguém foi à clínica buscando assistência psicológica, mas muitos pacientes foram encaminhados pelos médicos aos psicólogos, uma vez que apresentavam sintomas psicossomáticos. Depois de dois anos, em 2009, o MSF finalizou o projeto no Complexo do Alemão. Como afirma Tyler Fainstat, diretor executivo do MSF Brasil, em um relatório sobre o projeto (MÉDICOS SEM FRONTEIRAS, 2009):

O projeto foi uma resposta emergencial, desenvolvida para durar apenas dois anos. As pessoas aqui ainda estão expostas a muita pressão por todos os lados, e a violência é parte de suas vidas. Mas o número de embates armados e de 
feridos dentro do Complexo do Alemão tem diminuído, levando a menos casos de emergência - foco original do nosso projeto.

Além disso, alguns serviços de saúde também se tornaram disponíveis para os residentes, como as Unidades de Pronto Atendimento (UPAs) - apesar de estas ainda não estarem localizadas dentro do Complexo do Alemão e de as ambulâncias ainda não entrarem nas favelas do Complexo. Entre os anos de 2007 e 2009, de acordo com o mesmo relatório citado anteriormente, a equipe do MSF realizou 19 mil consultas médicas e 650 resgates de emergência, utilizando a ambulância customizada. Em relação à assistência psicológica, a equipe realizou 3 mil atendimentos a 1.300 pacientes, incluindo crianças e adultos.

Finalmente, refletindo sobre a experiência no Complexo do Alemão, um dos entrevistados concluiu: "O Brasil não precisa de modelos." Talvez a crença equivocada de que o MSF precisaria ajudar o Brasil a desenvolver novos modelos para lidar com problemas locais foi o primeiro e principal erro. "No Haiti, é importante desenvolver um novo modelo que possa ser incorporado pelo governo local. Mas, no Brasil, há muitos modelos estratégicos, como o SUS. O problema é que a maioria desses projetos não são colocados em prática”, ele acrescenta.

\section{Repensando a Ação Humanitária em Contextos de Violência Urbana}

O projeto do MSF no Complexo do Alemão foi definido por alguns entrevistados como uma "falha" ou um exemplo de um "mau momento" da organização. No entanto, alguns dos problemas e dilemas enfrentados pelo MSF no complexo de favelas cariocas ilustram desafios e questões mais gerais das organizações humanitárias ao atuar em situações de não guerra em áreas urbanas. Como argumentado 
aqui, esses dilemas podem ser resumidos segundo três principais questões apresentadas por atores humanitários para justificar sua presença nas favelas urbanas.

Primeiramente, o projeto do MSF reflete uma tentativa de destacar tanto a natureza universal dos processos de urbanização quanto a emergência da narrativa ao redor da concepção da "favela global". Baseado em experiências anteriores em contextos urbanos, o MSF pressupôs que a realidade do Alemão era similar a outras áreas pobres em cidades do Sul Global, particularmente no Haiti. Com base em um discurso acerca das necessidades dos moradores das favelas combinado à marginalização das favelas, a organização presumiu que essas pessoas não teriam acesso a serviços públicos nem seriam capazes de negociar o direito à cidade (LEFEBVRE, 1993). Tal compreensão dos moradores das favelas silencia uma longa história de engajamento dos residentes do Alemão - em sua maioria trabalhadores assalariados que circulam pela cidade e acostumados a lidar com serviços públicos ruins - com governantes e associações políticas. Consequentemente, aqueles que mais demandavam o serviço de emergência oferecido pelo MSF eram justamente os perpetradores da violência, i.e., os traficantes de drogas. Apesar de alguns humanitários considerarem tal fato aceitável, uma vez que o objetivo da ação humanitária é garantir o alívio do sofrimento humano independentemente de quem seja o beneficiário, não há dúvidas de que a situação no Alemão era tanto uma consequência não intencionada quanto uma questão ética para os trabalhadores do MSF. Em outras palavras, havia um claro conflito com o princípio de neutralidade e, para muitas organizações locais, o atendimento médico dos criminosos era percebido como um incentivo à violência. Um discurso de necessidades, nesse aspecto, não opera necessariamente no sentido oposto ao discurso do medo e da segurança. Ambas as abordagens ao problema da violência urbana são marcadas, igualmente, por certo silêncio em relação às políticas de proteção fundamentadas em direitos e justiça 
social. Apesar das intenções altruístas, o discurso que articula necessidades fomenta um tipo de individualidade e dependência que prejudica a consolidação da favela como um espaço da cidade governado por regras democráticas.

A premissa da universalidade, fundamentada na invenção da "favela global" como um novo espaço humanitário, apontou para uma intervenção que não dialogava com experiências e conhecimento prévios. Os trabalhadores do MSF não conheciam a dinâmica espacial e social do complexo de favelas, o que resultou em um mau planejamento acerca da localização da clínica, do tipo de assistência a ser provido, bem como da logística dos seus serviços vis-à-vis os provedores locais.

Além disso, a equipe do MSF desconhecia tanto a lógica institucional das unidades médicas, dificultando o encaminhamento dos pacientes aos hospitais da região, quanto a relação entre o uso de força, as vítimas e a natureza dos ferimentos e vulnerabilidades criadas. Tudo isso culminou na dificuldade do MSF de ter acesso aos feridos e, finalmente, em um viés seletivo na assistência médica. Em suma, a falta de conhecimento acerca da situação local, alimentada por uma compreensão universal e essencialista de vida e morte nas favelas, impediu a organização de criar um relacionamento com os serviços governamentais locais, de reconhecer a necessidade de um diálogo aberto com os moradores das favelas e seus líderes, e, finalmente, limitou sua capacidade de cuidar da população local.

O terceiro dilema refere-se à presença simultânea de temporalidades heterogêneas não relacionadas no complexo de favelas. A intervenção foi fundamentada em uma noção de uma emergência temporária e, por isso, apresentou uma natureza reativa. Foi motivada por um surto de violência e pela atenção da mídia à situação do Complexo do Alemão após forte operação policial na região em 2007. A mobilização da mídia nacional e internacional e de opiniões públicas sobre o 
complexo de favelas autorizou a atuação do MSF tanto em termos do mandato - reduzir o sofrimento em situações de violência - quanto em termos de experiência prévia - prover atendimento médico em situações de emergência. No entanto, um paradoxo temporal permeava a estratégia como um todo: por um lado, o MSF operou na lógica de emergências temporárias - projetos de curto a médio prazo com foco específico e um cronograma predefinido -; por outro lado, o Alemão era uma cidade em si mesma, constituída e produzida pelas rotinas diárias de seus moradores, pela presença ambígua de serviços governamentais e seu aparato repressivo, pelo engajamento histórico de associações de moradores com políticos locais e por uma rede complexa de provedores de serviço municipais, federais e não governamentais. A fim de garantir um espaço para as próprias atividades, o MSF precisou negociar através de diversas temporalidades e desenhos institucionais um difícil acordo que dependia de relações de longo prazo com atores comunitários e instituições governamentais. Uma vez que o MSF não coordenava a cadeia completa de provisão de serviços de saúde (como fez em Porto Príncipe), a cooperação com outros atores foi essencial mesmo com esta limitando sua autonomia organizacional. No entanto, a incapacidade da organização de estabelecer tais pontes de contato e cooperação resultou em um reduzido impacto das atividades na comunidade, que se reflete claramente no sentimento de indiferença dos moradores em relação à presença do MSF no Alemão.

Entretanto, é necessário ressaltar que a experiência do projeto no Alemão foi importante no processo de institucionalização do MSF no Brasil. A dificuldade de implementar projetos específicos em contextos urbanos, combinada ao crescimento do Brasil como ator global no campo humanitário e em discussões relevantes da agenda global do MSF (como doenças negligenciadas e acesso a medicamentos), provocou mudanças na natureza do escritório do MSF no país. Desde 2009, o MSF Brasil tornou-se um escritório institucional des- 
tinado a campanhas de advocacy, recrutamento e comunicação. Uma parte importante dos doadores do MSF está no Brasil, e o escritório é responsável por pressionar o governo brasileiro a priorizar e apoiar questões relativas à saúde global. É certo que o MSF ainda opera em situações muito específicas a partir de uma avaliação apropriada, como foi o caso do atendimento médico aos haitianos nas áreas fronteiriças do Brasil ao chegaram no país após o terremoto ocorrido no Haiti em 2010.

O crescimento da importância do MSF Brasil influenciou a participação ainda desigual dos membros do Sul Global nos processos de tomada de decisão da organização. Em um relatório sobre atividades do MSF no Brasil (MÉDICOS SEM FRONTEIRAS, 2007), foi reconhecido que:

\begin{abstract}
MSF é um movimento que ainda é muito orientado para os países ricos, europeus do Norte, e, como muitos outros escritórios e missões, a associação do MSF Brasil pode trazer novas ideias para o movimento internacional.
\end{abstract}

Finalmente, é possível afirmar que a incorporação de comunidades empobrecidas do Sul Global (que não são tradicionalmente concebidas como situações de conflito armado de acordo com o direito humanitário) apresenta desafios normativos e práticos para os humanitários. Estes podem criar consequências não intencionadas capazes de influenciar (e muitas vezes aumentar) a lógica da violência urbana; por exemplo, ao transpor o discurso da guerra - e consequentemente do inimigo - para contextos de vida urbana. As intervenções humanitárias nesses espaços urbanos podem interferir em disputas locais sobre os direitos e territórios, alterando a relação entre os atores locais e, às vezes, até mesmo desempenhando funções tradicionalmente do Estado. A favela demanda proteção, mas também é um espaço de disputas políticas. A provisão de serviços públicos deve ocorrer a partir de parcerias e do diálogo com a própria comunidade. 
Este argumento não deve ser compreendido como uma defesa do Estado nem como resistência ao humanitarismo. Esta é uma visão que defende maior sensibilidade política e que recusa a implementação de programas e projetos para as pessoas porque elas são moradores de favelas. Moradores de favelas são, primeiramente, moradores das cidades, para quem as soluções, prioridades e estratégias são definidas por $e$ para aqueles impactados por tais práticas. Se (e como) humanitários e governantes podem participar desses processos, esta deve ser uma decisão daqueles que, até hoje, permanecem excluídos (RANCIERE, 1998).

Nesse sentido, Sadako Ogata (1995, p. 25), ex-alta-comissária das Nações Unidas para Refugiados, estava certa ao afirmar que "não há soluções humanitárias para problemas humanitários”, em particular em outras situações de violência como a favela. Apesar da construção de contextos urbanos de violência, e de favelas em particular, como um ponto "fora da curva" dos espaços para ação humanitária, o que vemos é novamente a reprodução de alguns dos dilemas tradicionais do humanitarismo. Isso indica que, talvez, o problema resida não nas favelas, mas nas lógicas operacionais do próprio humanitarismo. ${ }^{20}$ Dessa forma, é possível argumentar que os moradores das favelas estão de fato em uma posição que apresenta alguns caminhos de ação possíveis, mas que certamente os humanitários globais não parecem ser a solução tão esperada por certos governos e agências humanitárias.

\section{Notas}

1. A expressão "Sul Global" tem sido crescentemente utilizada tanto no âmbito acadêmico quanto da política internacional para se referir aos Estados que se encontram nas regiões da América Latina e Central, África e grande parte da Ásia. Tal nomenclatura ganha importância após o fim da Guerra Fria com a 
perda da relevância das categorias "Leste" e "Oeste". Além disso, o fim da bipolaridade internacional traz um novo questionamento acerca do uso da categoria "terceiro mundo", tanto por ter sido utilizada muitas vezes anteriormente em referência aos Estados "não alinhados" à disputa entre Estados Unidos e União Soviética, quanto por remeter a uma concepção de atraso, não moderno ou não civilizado. Assim, acadêmicos e diplomatas têm optado por usar a categoria "Sul Global".

2. Para uma análise crítica sobre humanitarismo, ver, por exemplo, Rieff (2002), Terry (2002), Wheeler (2000), De Waal (1997), Calhoun (2008) e Chandler (2002).

3. Estes esforços são exemplificados no "Projeto Esfera", que reuniu diversas agências humanitárias com o objetivo de definir princípios comuns no que se refere à qualidade da ação humanitária e responsabilidade das organizações. Ver: $<$ http://www.sphereproject.org > . Os Códigos de Conduta da Cruz Vermelha Internacional e do Movimento do Crescente Vermelho e de ONGs que atuam em situações de desastre natural, financiados pelo CICV e pelo Interagency Standing Committee (formado por várias organizações humanitárias internacionais, como Caritas, CARE, Oxfam e Save the Children), também institucionalizaram normas comuns e procedimentos padrão. Para uma análise crítica dessas iniciativas, ver Terry (2002).

4. Para mais dados relativos aos processos de urbanização, ver UN-Habitat (2004) e Inter-Agency Standing Committee (2009).

5. Ver também Harroff-Tavel (2010).

6. Apesar do termo "favela" ter sido substituído por "comunidade" em estudos no campo da sociologia e na mídia em geral e por "aglomerado subnormal" na linguagem tecnocrática (incluindo o censo) a fim de evitar conotações pejorativas, este artigo mantém o uso do termo "favela" como forma de problematizar e discutir esses referenciais estereotipados.

7. Vale ressaltar que dados demográficos indicam que, de fato, a tendência à urbanização é concentrada nos países em desenvolvimento e menos desenvolvidos - e deve continuar assim nos próximos anos. Isso ocorre uma vez que as taxas de crescimento urbano já estabilizaram nos países desenvolvidos e que a maioria da população rural mundial - somada a taxas mais altas de crescimento populacional - é um fenômeno do terceiro mundo. Apesar disso, análises alarmistas e muitas vezes preconceituosas desses processos nos fazem questionar se cidades desenvolvidas no Ocidente não enfrentam também práticas de segregação territorial, alto nível de violência e crimes, bem como insegurança social e civil. Fora algumas exceções notáveis, como a experiência dos EUA com gue- 
tos e os banlieues em Paris, a literatura sobre humanitarismo acerca da violência urbana parece silenciar o caráter transnacional das vulnerabilidades e necessidades urbanas. Aqui, buscamos enfatizar que não há nada natural no encontro entre violência urbana e o aumento das favelas como um fenômeno do Sul Global. As favelas são extremamente diversas, seja dentro da mesma cidade ou em diferentes países, tornando difícil pensar sobre modelos gerais capazes de serem transpostos tranquilamente de um lugar para outro e a partir de um grupo de pessoas para outro.

8. É possível identificar, nessas análises, a produção discursiva das "cidades falidas", que demandam formas alternativas de intervenção, um movimento similar àquele que pesquisadores e tomadores de decisão adotaram em relação aos "Estados falidos" no final dos anos 1990. Para uma leitura crítica desses termos, ver Call (2008).

9. Ver, por exemplo, Lefebvre (1993), Harvey (1973) e Brenner (2009).

10. Para uma análise crítica sobre os mecanismos neoliberais de governança urbana através do estudo de caso sobre o México, ver Becker e Müller (2013).

11. Leite (2012) chama tais estratégias de modelo "Pereira Passos", em referência ao ex-prefeito do Rio de Janeiro (1902-1906). Pereira Passos ficou famoso pela reforma urbana da cidade, que buscou transformar o Rio em uma cidade moderna, cosmopolita e ocidental, tendo Paris como modelo. Remoções forçadas das comunidades mais pobres visaram limpar o centro da cidade. Aprimoramento da infraestrutura e reformas aumentaram o valor das moradias, forçando os antigos residentes a se mudar para os subúrbios e para algumas favelas já existentes. Mais tarde, planos de reforma urbana, incluindo tentativas de urbanizar e formalizar as favelas, integrando-as às cidades, como o projeto Favela Bairro em 1993, aumentaram o custo de vida nas favelas, dificultando a permanência dos antigos moradores. O alto custo para "se formalizar", através da regularização da terra e da propriedade, bem como dos serviços básicos, como eletricidade, água e telefonia, incentivou a apropriação desses territórios por recém-chegados e pelo negócio imobiliário. Essas estratégias significaram, portanto, a incorporação das favelas pela cidade por meio do mercado.

12. Apesar de algumas das atividades desenvolvidas pelos Peace Corps apresentarem um caráter essencialmente humanitário (i.e., focadas no alívio do sofrimento humano e assistência), a organização não deve ser concebida enquanto organização humanitária. Esta é uma inciativa do governo norte-americano que data da década de 1960 com o objetivo de aprimorar as relações dos Estados Unidos com os países em desenvolvimento por meio de projetos de assistência social. 


\section{Carolina Moulin e Jana Tabak}

13. Para mais informações sobre o projeto, ver: <http://www.urbansurvivors.org/>.

14. É importante notar que o MSF desenvolve projetos também em países desenvolvidos. Na Europa, grande parte do trabalho é dedicado a imigrantes, refugiados e solicitantes de refúgio, que são frequentemente discriminados e excluídos do sistema de assistência médica pública. Na França, o MSF trabalha desde 1987 com viciados em drogas e em áreas pobres da cidade. No entanto, países europeus representam apenas 5\% das atividades do MSF em todo o mundo. De acordo com o website da organização, o MSF opera em vinte cidades em todo o mundo.

15. Para uma análise crítica acerca das campanhas humanitárias, ver Boltanski (2004) e Chouliaraki (2010).

16. A expressão "cidade partida” foi cunhada por Zuenir Ventura (1992).

17. Durante 2012 e 2013 , as autoras entrevistaram uma série de humanitários que já trabalharam e outros que ainda trabalham no MSF Brasil e na Cruz Vermelha Brasileira. As informações sobre os projetos do MSF no país apresentadas neste artigo derivam desses encontros.

18. Referências específicas a países foram omitidas para preservar o anonimato das fontes.

19. As favelas que compõem o Complexo do Alemão são Palmeirinha, Vila Matinha, Casinhas, Parque Alvorada, Relicário e Morro das Palmeiras. Segundo o censo de 2010, o total de pessoas que moram no Complexo soma quase 13 mil.

20. Para análise crítica acerca de processos contemporâneos de ajuda humanitária e alívio do sofrimento humano, ver, por exemplo, Weiss (2013), Barnett (2011), Moyo e Ferguson (2009) e Fassin (2012).

\section{Referências Bibliográficas}

BARNETT, M. Empire of Humanity: A History of Humanitarianism. Ithaca: Cornell University Press, 2011.

; SNYDER, J. The Grand Strategies of Humanitarianism. In: BARNETT, M.; WEISS, T. (Ed.). Humanitarianism in Question: Politics, Power, Ethics. Ithaca: Cornell University Press, 2008. p.143-171. 
BECKER, A.; MÜLLER, M. The Securitization of Urban Space and the "Rescue" of Downtown Mexico City: Vision and Practice. Latin American Perspectives, v. 40, p. 77-94, 2013.

BOLTANSKI, L. Distant Suffering: Morality, Media and Politics. Cambridge: Cambridge University Press, 2004.

BRENNER, N. What is Critical Urban Theory? City, v. 13, n. 2-3, p. 198-207, 2009.

CALHOUN, C. The Imperative to Reduce Suffering. In: BARNETT, M.; WEISS, T. (Ed.). Humanitarianism in Question: Politics, Power, Ethics. Ithaca: Cornell University Press, 2008. p. 73-97.

CALL, C. The Fallacy of the "Failed State". Third World Quarterly, v. 29, n. 8, p. 1.491-1.507, 2008.

CHANDLER, D. From Kosovo to Kabul. Londres: Pluto Press, 2002.

CHOULIARAKI, L. Ordinary Witnessing in Post-Television News: Towards a New Moral Imagination. Critical Discourse Studies, v. 7, n. 4, p. 305-319, 2010.

DAVIS, M. Planet of Slums. Londres: Verso, 2006.

DE WAAL, A. Famine Crimes: Politics and the Disaster Relief Industry in Africa. Bloomington: Indiana University Press, 1997.

DUIJSENS, R. Humanitarian Challenges of Urbanization. International Review of the Red Cross, v. 92, n. 878, p. 351-368, 2010.

FASSIN, D. Humanitarian Reason: A Moral History of the Present. Berkeley: University of Californa Press, 2012.

FERRIS, E. The Politics of Protection: The Limits of Humanitarian Action. Washington, DC: Brookings Institution Press, 2011.

FREIRE-MEDEIROS, B. Gringo na laje: produção, circulação e consumo da favela turística. Rio de Janeiro: FGV Editora, 2009.

GALDO, Rafael. Rio é a cidade com maior população em favelas do Brasil. Políticas habitacionais estão longe de atender à demanda por moradias na cidade. O Globo, 21 dez. 2011. Disponível em: <http://oglobo.globo.com/pais/rio-acidade-com-maior-populacao-em-favelas-do-brasil-3489272>. Acesso em: 12 jan. 2013. 


\section{Carolina Moulin e Jana Tabak}

GLOBAL JUSTICE. Manifesto pela apuração das violações de direitos humanos cometidas na operação Complexo do Alemão. 2007. Disponível em: $<$ http://global.org.br/programas/manifesto-pela-apuracao-das-violacoesde-direitos-humanos-cometidas-na-operacao-complexo-do-alemao/>. Acesso em: 13 mar. 2013.

HARROFF-TAVEL, M. Violence and Humanitarian Action in Urban Areas: New Challenges, New Approaches. International Review of the Red Cross, v. 92, n. $878,2010$.

HARVEY, D. Social Justice and the City: Geographies of Justice and Social Transformation. Baltimore: Johns Hopkins University Press, 1973.

INTER-AGENCY STANDING COMMITTEE. Meeting Humanitarian Challenges in Urban Areas (MHCUA): Draft Assessment. 2 out. 2009. Disponível em: <http://www.humanitarian info.org/iasc>. Acesso em: 19 set. 2013.

KROONING, K.; KRUIJT, D. (Ed.). Fractured Cities: Social Exclusion, Urban Violence and Contested Spaces in Latin America. Londres: Zed Books, 2007.

LEFEBVRE, H. Le Droit à la ville. Paris: Ellipses, 1993.

LEITE, M. Territórios de insegurança e a luta pelos direitos. Trabalho apresentado no seminário "Human Rights and International Politics", Rio de Janeiro, 13 mai. 2012.

LUCCHI, E. Moving from the "Why" to the "How": Reflections on Humanitarian Response in Urban Settings. Disasters, v. 36, n. 1, 2012.

MÉDICOS SEM FRONTEIRAS. Notes on Field Associative Debate. Rio de Janeiro, 7 e 9 abr. 2007. Disponível em: <https:/www.msf.org.br/arquivos/ uploads/FADMSFBrazilReport2007.pdf>. Acesso em: 19 out. 2012.

. Living in Fear: Healing Mental Scars in Rio’s Slums. 2009. Disponível em: <http://www.msf.org.uk/article/living-fear-healing-mental-scars-riosslums>. Acesso em: 13 mar. 2013.

MOYO, D.; FERGUSON, N. Dead Aid. Nova York: Farrar, Straus e Giroux, 2009.

OGATA, S. Turbulent Decade: Confronting the Refugee Crises of the 1990s. Nova York: W.W. Norton, 1995. 
PATEL, R.; BURKE, T. Urbanization: An Emerging Humanitarian Disaster. The New England Journal of Medicine, v. 361, n. 8, 2012.

PERLMAN, J. Marginality: From Myth to Reality in the Favelas of Rio de Janeiro, 1969-2002. In: HANLEY, L.; RUBLE, B.; TULCHIN, J. (Ed.). Becoming Global and the New Poverty Crisis. Washington: Woodrow Wilson International Center for Scholars, 2007. p. 9-54.

RANCIERE, J. Disagreement: Politics and Philosophy. Minneapolis: University of Minnesota Press, 1998.

RIEFF, D. A Bed for the Night. Nova York: Simon and Shuster, 2002.

TERRY, F. Condemned to Repeat? The Paradoxes of Humanitarian Action. Ithaca: Cornell University Press, 2002.

UN-HABITAT. State of the World's Cities 2004-05: Globalization and Urban Culture. 2004. Disponível em: <http://mirror.unhabitat.org/pmss/listItemDetails.aspx?publicationID=1163>. Acesso em: jun. 2014.

VALLADARES, L. P. A invenção da favela: do mito de origem a favela.com. Rio de Janeiro: Fundação Getúlio Vargas, 2005.

VENTURA, Z. Cidade partida. Rio de Janeiro: Companhia das Letras, 1992.

WEISS, T. Humanitarian Business. Londres: Polity Press, 2013.

WHEELER, N. Saving Strangers. NovaYork: Oxford University Press, 2000.

\section{Resumo}

\section{Humanitarismo e a Favela Global: Violência Urbana e Ação Humanitária no Rio de Janeiro}

$\mathrm{O}$ artigo analisa criticamente os dilemas envolvidos nas recentes intervenções de organizações humanitárias internacionais em contextos urbanos do Sul Global. A inclusão de comunidades urbanas pobres - como as favelas do Rio de Janeiro - no escopo de atuação de atores humanitários resulta da compreensão particular que associa processos de urbanização à redefinição 
dos alvos da ação humanitária. O artigo argumenta que a transposição da proteção e assistência humanitária para outras situações de violência, como as favelas do Rio, está fundamentada na construção de favelas enquanto espaços marginais de insegurança e epítome de todos os problemas relacionados a processos urbanos em sociedades em desenvolvimento e menos desenvolvidas. Baseado em uma análise do projeto da organização Médicos Sem Fronteiras no Complexo do Alemão, no Rio de Janeiro, entre 2007 e 2009, o artigo conclui com uma discussão crítica acerca das consequências do reconhecimento e produção das favelas (e da favela global) como um problema de segurança e proteção, em que dimensões democráticas complexas das disputas políticas locais são silenciadas.

Palavras-chave: Ação Humanitária - Violência Urbana - Médicos Sem Fronteiras - Favelas - Rio de Janeiro

\section{Abstract}

\section{Humanitarism and the Global Favela: Urban Violence and Humanitarian Action in Rio de Janeiro}

The paper aims at investigating the dilemmas involved in the recent turn of international humanitarian organizations to urban areas of the Global South. The incorporation of impoverished urban communities - such as Rio de Janeiro's favelas - in the landscape of humanitarian action results from a particular reading that connects urbanization processes with a redefinition of the scope of humanitarian action. The paper argues that the transposition of humanitarian protection and assistance to other situations of violence, such as Rio's favelas, is premised on the construction of slums as marginal sites of insecurity and as the epitome of all problems related to urban processes in developing and underdeveloped societies. Based on a review of Médecins sans Frontières's project in Complexo do Alemão - Rio de Janeiro, from 2007 to 2009, the paper concludes with a critical reading of the consequences of recognizing favelas (and the global slum) as a problem of security and protection, without acknowledging the complex democratic dimensions of local political struggles.

Keywords: Humanitarian Action - Urban Violence - Médecins sans Frontières - Favelas - Rio de Janeiro 